\title{
Using Gantt Chart Software in Managing Student Team Projects
}

\author{
Gary B. Randolph \\ Purdue University School of Technology \\ Anderson, Indiana
}

\section{INTRODUCTION}

Student team projects have become a popular way to teach. Good teams develop an environment of effective adult learning andragogy, ${ }^{1}$ emphasizing student self-direction in their own learning, shared experiences, near-term application and performance feedback. But coaching teams and keeping them on track is a difficult and delicate job for faculty. ${ }^{2}$ The instructor cannot manage teams for students. Yet no one wants teams to flounder. Gantt chart software can help students manage their own teams, and, in the process, teach principles of project management and teamwork.

In a Computer Technology course on database development, students were assigned a team database development project. The team task was to design a complete database application in Microsoft Access, a popular database program. The finished project was to include the data design, data entry screens, query options, reports, and programming code for special functions.

Early in the semester, students were presented the requirements for the proposed database. Students were then placed into teams of 3-5 students. Class time was allotted for the teams to discuss the project and how they should proceed. They could ask questions of the "client," who was represented by the instructor. Then, after a short lecture on the concepts behind PERT and Gantt analysis, students were introduced to a special Gantt analysis software program they could use to help coordinate their efforts.

\section{GANTT SOFTWARE TOOL}

Gantt charting is a simple time-charting tool developed by Henry L. Gantt in $1917 .{ }^{3}$ Gantt charts are effective for scheduling projects and tracking their progress. In a Gantt chart, each task in a project is represented by a horizontal bar. The length of each bar indicates the time required to complete the task. Since some tasks cannot be begun until other tasks are completed, the position of each bar indicates when that task can be begun. The network of bars stretches out to indicate the total time required to complete the project. The strength of Gantt charting lies in its ability to make clear the interdependence of tasks that come together to create a completed project. ${ }^{3}$

To help the students manage their teams, a simplified Gantt analysis program was developed in Microsoft Access for the students' use. This, of course, was not the only software option. Microsoft Project, Micro Planner X-Pert from Micro Planning International, Milestones Etc. from Kidasa Software, and others serve the commercial market well. The current project, however, suggested a need to develop a homebrew project manager for several reasons. 
For one thing, compared to off-the-shelf project management software, developing the simplified Gantt application kept the learning curve low for students and allowed the instructor to stick to teaching course content rather than project management software. In addition, since the Gantt program was written in Microsoft Access it also gave students experience with an application similar to how their completed team project database program was to look and feel. Student teams used the Gantt methodology to set project tasks, interim benchmarks, and individual responsibilities in accomplishing goals.

Certain evaluation points were set by the instructor, such as due dates for the various phases of the project. Each student team decided what tasks needed to be completed before each evaluation point and which team member(s) were to be assigned to each task. Teams could also add their own intermediate evaluation points, such as team meetings and intra-team evaluations. The teams produced very good project schedules, such as the one shown in Figure 1.

Figure 1: Sample Student Team Gantt Printout

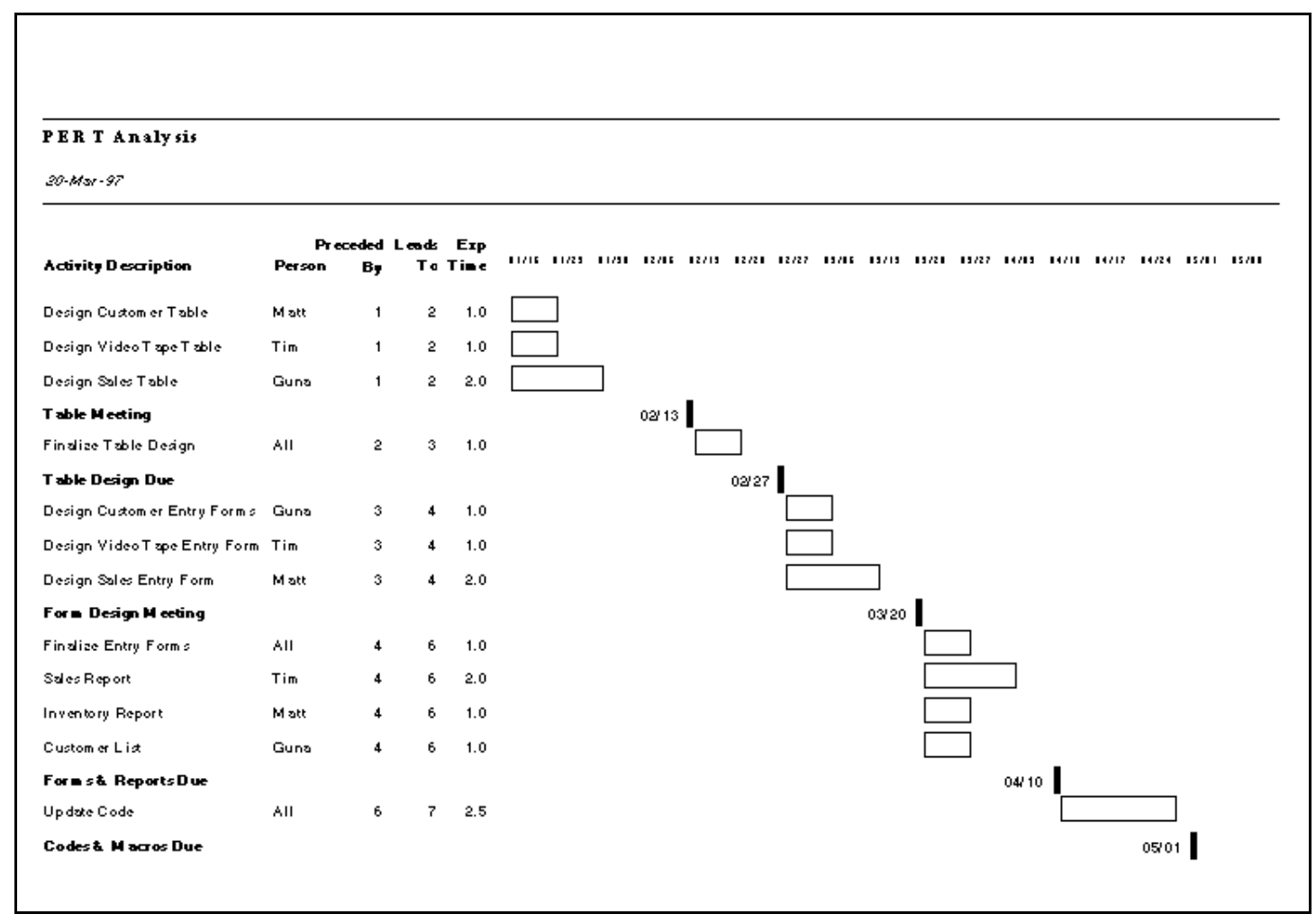

\section{RESULTS}

All teams finished their project on schedule. More significantly, students indicated that the using the Gantt software enhanced their learning, improved their team management, and increased their understanding and appreciation of Gantt analysis. 
Toward the end of the semester, students were asked to indicate agreement to a series of statements using a five-point Likert scale (1=strongly disagree, $5=$ strongly agree). The results are shown in Table 1. Students reported that following their experiences they believed a Gantt schedule was a good way to manage a project (4.27) and that the Gantt software helped their team plan their work (3.73). They also agreed that building the Gantt schedule helped them better understand Gantt analysis (4.09). Significant to curriculum design and the whole question of whether student team projects are worth the trouble, students believed that they learned more by building a complete database than they would have just using unrelated lab assignments (4.09).

\begin{tabular}{|l|r|}
\hline \multicolumn{2}{|c|}{ Table 1: Student Evaluation of Gantt Chart Experience } \\
\hline \multicolumn{2}{|c|}{$\begin{array}{r}\text { Student Responses } \\
(1=\text { strongly disagree, } \\
5=\text { strongly agree })\end{array}$} \\
\hline $\begin{array}{l}\text { I think a Gantt Chart is a good way to manage a project } \\
\text { analysis }\end{array}$ & 4.27 \\
\hline $\begin{array}{l}\text { I think I learned more by building a complete database } \\
\text { than I would have with unrelated lab assignments }\end{array}$ \\
\hline The Gantt chart helped my team plan our work & 3.09 \\
\hline
\end{tabular}

\section{CONCLUSIONS}

The Gantt software was successfully integrated into the course. The software was simple enough that it did not become a distraction from regular course content. As the student survey results indicate, it was helpful to the teams in managing their project work.

During the project, students took a high degree of ownership in their teams' work. Often in lab classes, each lab assignment stands as an independent entity with no relationship to previous or succeeding assignments. When graded lab assignments are returned to students, students often file them away without comment. However, in this case that did not happen. For instance, when papers were returned for the initial table design, students met in teams to discuss the instructor's comments and to ask questions. Knowing that their table design would be the basis for later work and later grades in designing entry forms, queries, and reports, students were not satisfied to just "take their grade." They wanted to understand everything that could be improved in the design.

The only downside of doing the Gantt analysis was that it was difficult for students who had never before built a database program to estimate the amount of time required to complete the various tasks. The instructor gave advice to help the students make those estimates. 
These results serve to encourage the use of on-going student projects as effective learning exercises. They also serve to encourage having teams coordinate themselves with Gantt-type analysis to improve both team management and androgogical learning.

\section{BIBLIOGRAPHY}

1. Knowles, M.S. (1980.) The Modern Practice of Adult Education. Chicago, IL: Association Press, Follett Publishing Company.

2. Schelnutt, W., Allen, M., Badami, V., Buch, K., Edwards, A., Ensley, C., Graham, J., Schmidt, D., Middleton, S., Phillips, H., Tolley, P., \& Lumsdaine, M. (1997). A Multidisciplinary Course Sequence Stressing Team Skills, Conceptual Design, Creative Problem Solving, Professional Practice, and Computing Skills for Students Entering The William States Lee College of Engineering. 1997 ASEE Annual Conference Proceedings [CD-ROM]. Washington, DC: American Society for Engineering Education.

3. Whitten, J.L., Bentley, L.D., Barlow, V.M. (1994). Systems Analysis \& Design Methods, Third Edition Burr Ridge, IL: Irwin.

\section{BIOGRAPHICAL INFORMATION}

GARY RANDOLPH is an assistant professor of Computer Technology at Purdue University, Anderson, Indiana campus. He teaches courses in database design, systems analysis, and data communications. He is a member of ASEE and the Association for Information Systems. He earned a B.S. at Taylor University and an M.A. at Ball State University. In addition to teaching he maintains an active consulting practice to local business. 